\title{
Factors Associated with Impaired Lung Function among Pregnant Women in Selected Rural and Urban Settings of the Copperbelt Province of Zambia
}

\author{
David Mulenga (MPH), Seter Siziya (PhD)
}

\author{
davykdn@gmail.com \\ *Corresponding Author: David Mulenga, Michael Chilufya Sata School of Medicine, Copperbelt University, Ndola, \\ Zambia.
}

\begin{abstract}
Background Information: Impaired lung function among women in developing countries remains a major public health problem.Factors influencing this important respiratory condition are not well characterized. The objective of our study was to explore factors associated with impaired lungfunction among pregnant women attending antenatal services at selected primary health care facilities in Ndola and Masaiti, Zambia.
\end{abstract}

Methods: Data on background, prenatal and environmental characteristics including spirometry resultswas obtained in a cross sectional study. A sample size of 1170 was computed and factors associated with impaired lung function among pregnant women were determined in the multivariate logistic regression. Spirometrywas determined using a spirometer, MIR Spirobank-G (Italy) with an attached printout of forced vital capacity (FVC), forced expiratory volume in 1 second (FEV1), and FEV1/FVC\% ratio. Lung function parameters of interest were categorized as follows: Normal FEV1/FVC\%: >70, Normal FEV1\%: > 80 and Normal FVC\%: > 80. Cooking fuel type was categorized as charcoal, wood, crop residues or electricity. While kitchen type was classified as enclosed, semi-open and open kitchen. Data analysis using SPSS version 16 used to present frequencies and proportions of population characteristics. Determinants of impaired lung function identified in the multivariate analysis.

Results: Out of a total sample of 1210 pregnant women, the study achieved a response rate of $96.7 \%$. Distribution of cooking fuel types was such that charcoal had an overall rate of slightly more than half (52.3\%) followed by wood (14.8\%). More people used electricity in the urban (15.5\%) compared to rural area (2.5\%). Our current study only found two factors independently associated with impaired lung function, cooking fuel type and gravidity. Use of crop residues as cooking fuel was 57\% less likely [AOR: 0.43, 95\% CI $(0.24,0.76)]$ to cause impaired lung function compared to using electricity. A primigravida was $24 \%$ more likely to [AOR: 1.24, 95\% CI $(1.03,1.50)]$ have impaired lung function compared with a multigravida.

Conclusion: Monitoring of respiratory disease using spirometry needs to be included in the primary health care package and interventions to prevent impaired lung functions in women in general should target advocacy for cleaner cooking fuel types for the poor women in developing countries where biomass is the predominant cooking fuel type.

Keywords: Spirometry, biomass, lung function, respiratory symptoms.

\section{INTRODUCTION}

Impaired lung function, indicated by a reduction in the forced vital capacity (FVC) and forced expiratory volume measured in the first second of exhalation $\left(\mathrm{FEV}_{1}\right)$, contributes significantly to several major health problems (Baines et al, 2015). Poor lung function has a predictive or even causal role in a wide range of conditions, not only respiratory disease but also considered as a significant predictor of adverse cardiovascular events. According to Min et al,. 2014, impaired lung functionis associated with an increased risk of coronary artery disease (CAD), stroke, and cardiovascular death. The exact mechanism for the 
Factors Associated with Impaired Lung Function among Pregnant Women in Selected Rural and Urban Settings of the Copperbelt Province of Zambia

association is not clear; however low-grade systemic inflammation has been identified as a plausible mechanistic pathway (Sabia et al, 2010). According to Gan et al, 2004, the circulating inflammatory markers, such as interleukin (IL)-6, fibrinogen and C-reactive protein (CRP) are high in individuals who have a declined FVC or FEV1 compared with those with normal pulmonary function. In the study by Baines etal, the influence of systemic inflammation and macrophage activation on lung function was assessed using regression modeling and both CRP and sCD163 had a significant negative effect on $\mathrm{FEV}_{1}$ and FVC. The mechanisms of the adverse effect of sCD163 were attributed to other factors driving systemic inflammation and these included microbial colonization, other environmental exposures or reverse causation (Baines et al, 2015).

There are a number of risk factors of impaired lung function and the known risk factors of lung impairment according to Hole etal, 1996 are age, smoking habit, diastolic blood pressure, serum cholesterol concentration, body mass index, and social class. Other researchers' (Lin et al, 2006) findings also indicate results that imply that obesity and insulin resistance are common pathways underlying lung function impairment and metabolic syndrome. A study among adult patients with stable non-cystic fibrosis bronchiectasis, showed chronic colonization with Pseudomonas aeruginosa (PA), more frequent severe exacerbations and more systemic inflammation as independent factors associated with an impaired lung function as opposed to the most expected factors namely, the long-term treatment strategies, such as the inhaled or oral steroids, long-acting inhaled bronchodilators, oxygen therapy, secretion clearance maneuvers, or antibiotics (Martínez-García et al, 2007).

Therefore, since a large body of evidence that (Eaton et al, 1999; Ebi-Kryston, 1988; Cook and Shaper, 1988; Kannell 1983; Strachan 1991; Tockman and Comstock, 1989) impaired lung function is a major clinical indicator of mortality risk in men and women for a wide range of diseases exist, the use of FEV1and FVC as part of any health assessment of patients should be considered. Moreover, pulmonary function test should be applied as an additional evaluation for metabolic syndrome in a clinical setting. In Zambia, research on lung functions has been conducted by Siziya, 2005 among persons exposed to cement dust and recently by Shonga and Siziya, 2016 among fuel attendants but there has never been a study to characterize the factors associated with impaired lung function in general. This study therefore, aims at exploring the factors associated with impaired lung function among pregnant women living in rural and urban areas of Copperbelt province in Zambia.

\section{METHODS}

A cross sectional study among pregnant women recruited from antenatal clinics in rural and urban settings of the Copperbelt province of Zambia was conducted between May, 2017 and March, 2018. A structured questionnaire was used to obtain information on background characteristics and symptoms of respiratory conditions. Lung functions were determined using a spirometer, MIR Spirobank-G (Italy) with an attached printout of forced vital capacity (FVC), forced expiratory volume in 1 second (FEV1), and FEV1/FVC\% ratio. The spirometer was calibrated to suit individual participant according to sex, age, height and weight.For each assessment a research nurse demonstrated the technique to the participant. The participants then performed some practice efforts. They were then required to perform a minimum of three reproducible FVC measures (within 5\% of maximum FVC produced). The output that produced the highest sum of FVC and FEV1 were used in the analyses. Women who could not perform three reproducible measures or who were unable to attempt the lung function assessment were excluded. All assessments were carried out by one of the nine research nurses who were trained to carry out the assessment in a similar manner.

Data Processing and Anallysis: Lung function parameters of interest were categorized as follows: Normal FEV1/FVC\%: >70, Normal FEV1\%: > 80 and Normal FVC\%: $>80$ according to the cutoff points based on the spirometry in practice manual, 2005. A practical guide to using spirometry in primary care (www.brit-thoracic.org.uk/copd). In the logistic regression, categories mild to severe were classified as impaired lung function. Preliminary analysis involving bivariate analysis was conducted in Epi Info. The Multivariate Regression Analysis correlations included age, height, weight, marital status, religion, ethnic background, use of traditional herbs, cooking 
Factors Associated with Impaired Lung Function among Pregnant Women in Selected Rural and Urban Settings of the Copperbelt Province of Zambia

fuel, history/current diabetes, hypertension, occupation, gravidity, systolic and diastolic blood pressure, body mass index, passive smoking (SHS), income, alcohol, smoking, educational status and the three parameters of the pulmonary functions namely FEV1, FVC and FEV1/FVC ratio. The independent predictors of outcome were obtained using the stepwise logistic regression in SPSS. The Step-wise multivariate linear regression analysis was done with lung function indices as dependent variables FEV1, FVC and FEV1/ FVC ratio. Magnitudes of association were estimated using odds ratios and their $95 \%$ confidence intervals. Statistical significance was set at $5 \%$.

Ethical Consideration: The project was approved by the tropical Diseases Research Centre (TDRC) Ethics Committee. Further approval was obtained from the Zambia Health Research Authority of the Ministry of Zambia and permission to conduct research in the ANC departments of the selected health facilities was obtained from the relevant authorities. Participants were reassured of confidentiality regarding their information and a consent form was signed before inclusion in the study. Participants were free to withdraw from the study at any time without any reparcations.

\section{RESULTS}

\section{Background Characteristics}

Table 1 presents a summary of population characteristics, out of a total of 1, 210 pregnant women recruited from the nine antenatal clinics (ANC), forty (3.3\%) pregnant women were excluded from the analysis due to incompleteness of data and failure to perform three reproducible spirometry measures or failure to attempt the lung function assessment, leaving a total of 1,170 participants for analysis. Majority (80\%) of the participants enrolled in the study were $35 y e a r s$ and below. Close to three thirds (91.2\%) of the participants were married and over half (54.6\%) had attained secondary and a third (30.0\%) primary education. Above two thirds of the participants (69.6\%) were unemployed housewives. Over a three quarters of participants (87.8\%) were taking nutritional supplements(ferrous sulphate and folic acid) and about the same proportion (84.6\%) were under malaria chemo prophylaxis - Fansida. Close to one fifth (19.7\%) of participants tookalcohol and only $3.1 \%$ cigarette smoking in pregnancy. Hypertension was reported in $3.7 \%$ and diabetes in $1.8 \%$.

Table 1. showing population characteristics of the study participants

\begin{tabular}{|c|c|c|c|c|c|c|}
\hline \multirow{2}{*}{ Background characteristics } & \multicolumn{2}{|c|}{ Total } & \multicolumn{2}{c|}{ Rural } & \multicolumn{2}{c|}{ Urban } \\
\cline { 2 - 7 } & $(\mathrm{n})$ & $\%$ & $(\mathrm{n})$ & $\%$ & $(\mathrm{n})$ & $\%$ \\
\hline Age & & & & & & \\
\hline $16-19$ & $(153)$ & 13.1 & $(71)$ & 14.8 & $(82)$ & 11.9 \\
\hline $20-24$ & $(407)$ & 34.8 & $(152)$ & 31.6 & $(255)$ & 37.0 \\
\hline $25-29$ & $(295)$ & 25.2 & $(110)$ & 22.9 & $(185)$ & 26.9 \\
\hline $30-34$ & $(215)$ & 18.4 & $(101)$ & 21.0 & $(114)$ & 16.5 \\
\hline $35-39$ & $(86)$ & 7.4 & $(43)$ & 8.9 & $(43)$ & 6.2 \\
\hline $40-44$ & $(14)$ & 1.2 & $(4)$ & 0.8 & $(10)$ & 1.5 \\
\hline Marital status & & & & & & \\
\hline Married & $(1069)$ & 91.4 & $(443)$ & 92.1 & $(626)$ & 90.9 \\
\hline Casual/cohabiting & $(82)$ & 7.0 & $(28)$ & 5.8 & $(54)$ & 7.8 \\
\hline Single & $(5)$ & 0.4 & $(3)$ & 0.6 & $(2)$ & 0.3 \\
\hline Divorced or Separated & $(14)$ & 1.2 & $(7)$ & 1.5 & $(7)$ & 1.0 \\
\hline Education & & & & & & \\
\hline Never attended school & $(55)$ & 4.7 & $(31)$ & 6.4 & $(24)$ & 3.5 \\
\hline Primary level & $(361)$ & 30.9 & $(162)$ & 33.7 & $(199)$ & 28.9 \\
\hline Secondary level & $(636)$ & 54.4 & $(257)$ & 53.4 & $(379)$ & 55.0 \\
\hline Tertiary & $(181)$ & 10.1 & $(31)$ & 6.4 & $(87)$ & 12.6 \\
\hline
\end{tabular}


Factors Associated with Impaired Lung Function among Pregnant Women in Selected Rural and Urban Settings of the Copperbelt Province of Zambia

\begin{tabular}{|c|c|c|c|c|c|c|}
\hline Occupation & & & & & & \\
\hline Office job & $(804)$ & 68.7 & $(315)$ & 65.5 & $(489)$ & 71.0 \\
\hline Housewife/unemployed & $(40)$ & 3.4 & $(17)$ & 3.5 & $(23)$ & 3.3 \\
\hline Trader & $(58)$ & 5.0 & $(21)$ & 4.4 & $(37)$ & 5.4 \\
\hline Street vender & $(27)$ & 2.3 & $(12)$ & 2.5 & $(15)$ & 2.2 \\
\hline Fishmonger & $(172)$ & 14.7 & $(88)$ & 18.3 & $(84)$ & 12.2 \\
\hline Farmer & (69) & 5.9 & $(28)$ & 5.8 & $(41)$ & 6.0 \\
\hline \multicolumn{7}{|l|}{ Maternal factors } \\
\hline \multicolumn{7}{|l|}{ Gravidity } \\
\hline Primigravida & $(272)$ & 23.2 & $(129)$ & 26.8 & $(143)$ & 20.8 \\
\hline multigravida & $(898)$ & 76.8 & $(352)$ & 73.2 & $(546)$ & 79.2 \\
\hline \multicolumn{7}{|l|}{ Diabetes } \\
\hline Yes & $(16)$ & 1.4 & $(0)$ & 0.0 & $(16)$ & 2.3 \\
\hline No & $(1154)$ & 98.6 & $(481)$ & 100.0 & $(673)$ & 97.7 \\
\hline \multicolumn{7}{|l|}{ Hypertension } \\
\hline Yes & $(36)$ & 3.1 & $(4)$ & 0.8 & $(32)$ & 4.6 \\
\hline No & $(1134)$ & 96.9 & $(477)$ & 99.2 & $(657)$ & 95.4 \\
\hline \multicolumn{7}{|l|}{ Body Mass Index } \\
\hline Under weight & $(516)$ & 44.1 & $(205)$ & 42.6 & $(311)$ & 45.1 \\
\hline Normal weight & $(368)$ & 31.5 & $(150)$ & 31.2 & $(218)$ & 31.6 \\
\hline Over weight & $(165)$ & 14.1 & $(80)$ & 16.6 & $(85)$ & 12.3 \\
\hline Obese & $(72)$ & 6.2 & $(28)$ & 5.8 & $(44)$ & 6.4 \\
\hline Severe obese & (49) & 4.2 & $(18)$ & 3.7 & (31) & 4.5 \\
\hline \multicolumn{7}{|l|}{ Smoke cigarettes } \\
\hline Yes & $(32)$ & 2.7 & (7) & 1.5 & $(25)$ & 3.6 \\
\hline No & $(1138)$ & 97.3 & $(474)$ & 98.5 & $(664)$ & 96.4 \\
\hline \multicolumn{7}{|l|}{ Fuel type for cooking } \\
\hline Wood & $(622)$ & 53.2 & $(271)$ & 56.3 & $(351)$ & 50.9 \\
\hline Crop residue & $(229)$ & 19.6 & $(174)$ & 36.2 & $(55)$ & 8.0 \\
\hline Charcoal & $(29)$ & 2.5 & $(18)$ & 3.7 & $(11)$ & 1.6 \\
\hline Electricity & $(119)$ & 10.2 & $(12)$ & 2.5 & $(107)$ & 15.5 \\
\hline Missing & $(171)$ & 14.6 & $(6)$ & 1.2 & $(165)$ & 23.9 \\
\hline
\end{tabular}

Respiratory Symptoms of the Pregnant Women and wheezing (32.2\%) present a higher proportion of in the Study Population

Table 2 gives a summary of the maternal respiratory symptoms in the study population and indicates that $3.1 \%$ of pregnant women did not have any respiratory symptoms. The general overview of the results show that urban area has more respiratory symptoms compared to theruralarea. Sputumproduction (29.6\%) maternal respiratory symptoms compared to the rest of the symptoms. The proportions show that these symptoms are the highest in rural areas with the rural recording $29.8 \%$ for sputum production and $33.3 \%$ for wheezing while the urban, showed $29.5 \%$ for sputum and $31.3 \%$ wheezing giving an overall population $22.8 \%$. 
Factors Associated with Impaired Lung Function among Pregnant Women in Selected Rural and Urban Settings of the Copperbelt Province of Zambia

Table 2. showing proportions of maternal respiratory symptoms according to region

\begin{tabular}{|c|c|c|c|c|c|c|c|}
\hline \multirow{2}{*}{ Respiratory symptoms } & \multicolumn{2}{|c|}{ Total } & \multicolumn{2}{c|}{ Rural } & \multicolumn{2}{c|}{ Urban } \\
\cline { 2 - 7 } & & $(\mathrm{n})$ & $\%$ & $(\mathrm{n})$ & $\%$ & $(\mathrm{n})$ & $\%$ \\
\hline \multirow{3}{*}{ symptoms } & Yes & $(36)$ & 3.1 & $(9)$ & 1.9 & $(27)$ & 3.9 \\
\cline { 2 - 8 } & No & $(1133)$ & 96.9 & $(471)$ & 98.1 & $(662)$ & 96.1 \\
\hline \multirow{3}{*}{ cough } & Yes & $(164)$ & 14 & $(51)$ & 10.6 & $(113)$ & 16.4 \\
\cline { 2 - 8 } & No & $(1005)$ & 86 & $(429)$ & 89.4 & $(576)$ & 83.6 \\
\hline \multirow{2}{*}{ Sputum } & Yes & $(346)$ & 29.6 & $(143)$ & 29.8 & $(203)$ & 29.5 \\
\cline { 2 - 8 } & No & $(823)$ & 70.4 & $(337)$ & 70.2 & $(486)$ & 70.5 \\
\hline \multirow{3}{*}{ Wheezing } & Yes & $(376)$ & 32.2 & $(160)$ & 33.3 & $(216)$ & 31.3 \\
\cline { 2 - 8 } & No & $(793)$ & 67.8 & $(320)$ & 66.7 & $(473)$ & 68.7 \\
\hline \multirow{2}{*}{ Nasal symptoms } & Yes & $(147)$ & 12.6 & $(75)$ & 15.6 & $(72)$ & 10.4 \\
\cline { 2 - 8 } & No & $(1022)$ & 87.4 & $(405)$ & 84.4 & $(617)$ & 89.6 \\
\cline { 2 - 8 } & Yes & $(83)$ & 7.1 & $(35)$ & 7.3 & $(48)$ & 7 \\
\hline \multirow{2}{*}{ Throat symptoms } & $(1086)$ & 92.9 & $(445)$ & 92.7 & $(641)$ & 93 \\
\cline { 2 - 7 } & Yes & $(17)$ & 1.5 & $(7)$ & 1.5 & $(10)$ & 1.5 \\
\hline
\end{tabular}

Lung Function Test Results of the Pregnant Women in the Study Population

With regard to FEV1/FVC, only $0.7 \%$ of pregnant women in the overall study population presented with a reduced FEV1/FVC. There was a significant association ( $\mathrm{p}$ value $=0.019$ ) between FEV1 and region. Rural area recorded $34.1 \%$ of mild obstruction while urban area recorded 39.8 mild obstruction and $1.5 \%$ moderate obstruction. The FVC in the overall population showed mild reduction and moderate reduction in $37.4 \%$ and $26.9 \%$ of pregnant women respectively.

Table 3. showing proportions of lung function parameters by region

\begin{tabular}{|c|c|c|c|c|c|c|c|c|}
\hline & & \multicolumn{2}{|c|}{ Total } & \multicolumn{2}{|c|}{ Rural } & \multicolumn{2}{|c|}{ Urban } & \multirow{2}{*}{ p-value } \\
\hline & & (n) & $\%$ & $(\mathrm{n})$ & $\%$ & $(\mathrm{n})$ & $\%$ & \\
\hline \multirow{3}{*}{ FEV1/FVC } & $<70$ & (8) & 0.7 & $(2)$ & 0.4 & (5) & 0.7 & \multirow{3}{*}{0.164} \\
\hline & 70 & (1) & 0.1 & (1) & 0.2 & $(0)$ & 0 & \\
\hline & $>70$ & $(1161)$ & 99.3 & $(478)$ & 99.4 & $(684)$ & 99.3 & \\
\hline \multirow{3}{*}{ FEV1 } & Moderate Obstruction & (13) & 1.1 & $(0)$ & 0 & $(10)$ & 1.5 & \multirow{3}{*}{0.019} \\
\hline & Mild Obstruction & $(449)$ & 38.4 & $(164)$ & 34.1 & $(274)$ & 39.8 & \\
\hline & Normal & $(708)$ & 60.5 & (317) & 65.9 & $(405)$ & 58.8 & \\
\hline \multirow{3}{*}{ FVC } & Moderate Reduction & $(315)$ & 26.9 & $(135)$ & 28.1 & $(183)$ & 26.6 & \multirow{3}{*}{0.435} \\
\hline & Mild Reduction & $(438)$ & 37.4 & $(167)$ & 34.7 & $(264)$ & 38.3 & \\
\hline & Normal & $(417)$ & 5.6 & $(179)$ & 37.2 & $(242)$ & 5.1 & \\
\hline \multirow{2}{*}{$\begin{array}{l}\text { Lung function } \\
\text { Impairment }\end{array}$} & Yes & $(267)$ & 22.8 & (121) & 25.2 & $(146)$ & 21.2 & \multirow{2}{*}{0.129} \\
\hline & No & (903) & 77.2 & $(360)$ & 74.8 & (543) & 78.8 & \\
\hline
\end{tabular}

The result of the bivariate analysis indicates that there is a statistically significant association between lung function result and region. Proportions of pregnant women from the rural area with impaired lung function were less than urban area. In the urban area, $1.5 \%$ of individuals presented with moderate obstruction (FEV1) compared to none in the urban area. Mild obstruction (FEV1) among the rural women were $39.8 \%$ compared to the urban area with $34.1 \%$. At this level of analysis, only two factor 
Factors Associated with Impaired Lung Function among Pregnant Women in Selected Rural and Urban Settings of the Copperbelt Province of Zambia

were significantly associated with impaired lung house ( $p$ value 0.005 ) and gravidity at $p$ value function at $10 \%$ level of significance and these are the type of fuel for cooking and warming the 0.056 . Table 4 summarizes the findings of the bivariate analyses.

Table 4. factors associated with impaired lung function in bivariate analyses

\begin{tabular}{|c|c|c|c|c|c|}
\hline \multirow{2}{*}{ Factor } & \multicolumn{2}{|c|}{ Yes } & \multicolumn{2}{|c|}{ No } & \multirow{2}{*}{$\mathrm{p}$ value } \\
\hline & (n) & $\%$ & (n) & $\%$ & \\
\hline \multicolumn{6}{|l|}{ Age } \\
\hline $16-19$ & $(118)$ & 13.1 & $(35)$ & 13.1 & 0.135 \\
\hline $20-24$ & $(327)$ & 36.2 & $(80)$ & 30 & \\
\hline $25-29$ & $(225)$ & 24.9 & $(70)$ & 26.2 & \\
\hline $30-34$ & $(166)$ & 18.4 & $(49)$ & 18.4 & \\
\hline $35-39$ & (58) & 6.4 & $(28)$ & 10.5 & \\
\hline $40-44$ & (9) & 1 & (5) & 1.9 & \\
\hline \multicolumn{6}{|l|}{ Education } \\
\hline No education & $(44)$ & 4.9 & $(11)$ & 4.1 & 0.752 \\
\hline Primary & $(272)$ & 30.1 & $(89)$ & 33.3 & \\
\hline Secondary & $(142)$ & 53.2 & $(636)$ & 54.4 & \\
\hline Tertiary & $(25)$ & 9.4 & $(118)$ & 10.1 & \\
\hline \multicolumn{6}{|l|}{ Cigarette } \\
\hline Smoker & (23) & 2.5 & (9) & 3.4 & 0.609 \\
\hline Non smoker & $(880)$ & 97.5 & $(258)$ & 96.6 & \\
\hline \multicolumn{6}{|l|}{ Fuel for cooking } \\
\hline Charcoal & $(475)$ & 52.6 & $(147)$ & 55.1 & 0.006 \\
\hline Wood & $(176)$ & 19.5 & (53) & 19.9 & \\
\hline Crop residue & $(17)$ & 1.9 & $(12)$ & 4.5 & \\
\hline Electricity & $(105)$ & 11.6 & $(14)$ & 5.2 & \\
\hline Combined source & $(130)$ & 14.4 & $(41)$ & 15.4 & \\
\hline \multicolumn{6}{|l|}{ Kitchen type } \\
\hline Enclosed & $(385)$ & 42.6 & $(120)$ & 44.9 & 0.540 \\
\hline Semi-detached & (399) & 44.2 & $(108)$ & 40.4 & \\
\hline Open space & $(119)$ & 13.2 & $(39)$ & 14.6 & \\
\hline \multicolumn{6}{|l|}{ Gravida } \\
\hline Prime gravida & $(222)$ & 24.6 & $(50)$ & 18.7 & 0.056 \\
\hline Multigravida & $(681)$ & 75.4 & $(217)$ & 81.3 & \\
\hline \multicolumn{6}{|l|}{ Body Mass Index } \\
\hline Under weight & $(402)$ & 44.5 & $(114)$ & 42.7 & 0.881 \\
\hline Normal weight & $(280)$ & 31 & $(88)$ & 33 & \\
\hline Over weight & $(125)$ & 13.8 & $(40)$ & 15 & \\
\hline Obese & $(56)$ & 6.2 & $(16)$ & 6 & \\
\hline Severe obese & $(40)$ & 4.4 & (9) & 3.4 & \\
\hline \multicolumn{6}{|l|}{ Blood Pressure } \\
\hline High BP & $(27)$ & 3 & (9) & 3.4 & 0.909 \\
\hline Normal BP & $(876)$ & 97 & $(258)$ & 96.6 & \\
\hline
\end{tabular}


Factors Associated with Impaired Lung Function among Pregnant Women in Selected Rural and Urban Settings of the Copperbelt Province of Zambia

\section{Multivariate Regression Analysis}

According to the results obtained in the multivariate analysis, a statistically significant association between the type of cooking fuel and impaired lung function was observed. A pregnant woman who used crop residue for cooking was 57\% less likely [AOR:0.43, $95 \% \mathrm{CI}(0.26,0.69)]$ to have impaired lung function compared to a pregnant woman who used electricity.

Gravidity was significantly associated with impaired lung function. A primigravida was $24 \%$ more likely[AOR:1.24, 95\% CI $(1.03,1.50)]$ to have impaired lung function compared with a multigravida. Table 5 presents a summary of the factors associated with impaired lung function at multivariate level.

Table 5. Independent factors associated with impaired lung function

\begin{tabular}{|c|c|}
\hline FACTOR & Adjusted OR at 95\% C.I \\
\hline $\begin{array}{c}\text { Type of cooking fuel } \\
\text { cooking }\end{array}$ & \\
\hline Charcoal & $1.00(0.75,1.32)$ \\
\hline Wood & $1.01(0.72,1.40)$ \\
\hline Crop residue & $0.43(0.24,0.76)$ \\
\hline Electricity & 1 \\
\hline Gravidity & \\
\hline Primigravida & $1.24(1.03,1.50)$ \\
\hline Multigravida & 1 \\
\hline
\end{tabular}

\section{Discussion}

The study found a high prevalence of impaired lung function in the rural at $25.2 \%$ compared to the urban area at $21.2 \%$ giving an overall prevalence of $22.8 \%$. This finding is comparable to many other studies (Kurmi et al. 2013; da Silver et al. 2012; Sumer et al. 2004) comparing lung functions between the rural and urban women, indicating that rural based women have lower lung functions compared to urban women. The age group 20-25 years old recorded the highest proportion of impaired lung function compared to the rest of the age groups although age was not statistically significantly associated with impaired lung function at both bivariate and multivariate analyses.This finding is however not consisted with other studies for instance a study done by Baines et al. 2015 showed that age was significantly associated with a low FVC and indicated that advancing age had negative effects on lung function especially $\mathrm{FEV}_{1}$ and FVC. Compared to rural areas, a large proportion of pregnant women from the urban area had impaired lung functions. On the other hand, there were more pregnant women with respiratory symptoms in the rural compared to the urban area and sputum production and wheezing recorded higher proportions compared to the rest of the symptoms.

Findings regarding impaired lung function among women have been documented by many investigators with inconsistent conclusions. Our current study, however, observed that cooking fuels have a significant effect on lung functions. Women using crop residue as cooking fuel were less likely to have impaired lung function compared to the women using electricity. This is an unexpected result and the possible explanation to this is that crop residues are mainly used in rural areas for cooking and in these areas cooking is done outside the house, hence less or sometimes no exposure to indoor emissions. Electricity users have recorded impaired lung functions because majority of such women use also charcoal a form of biomass and due to its nature they use it indoor and emissions from these affect their lung functions. This finding is in contrast with the findings by Rinne et al. 2006 who reported significantly lower $\mathrm{FEV}_{1}$ and $\mathrm{FVC}$ values among household members predominantly using biomass compared with those using other fuel types. This expected observation maybe attributed to the effects of pollutants emitted by these unprocessed cooking fuel types (Pope et al. 2015)on lung functions. The unexpected finding of our study was that FEV1 showed a significant difference between rural and urban with a higher proportion of a declined FEV1 being observed in the urban area compared to the rural area. This result may be explained by the fact that most urban households in our study sample used charcoal (a form of biomass fuel) for cooking and cooked indoors compared to the rural households who predominantly cook outdoors. Therefore, poor ventilation in the urban study population would concentrate pollutants in the cooking area thus aggravating the adverse effects of biomass smoke on lung function. This observation is in accord with the observations by other researchers (Brue et al. 2000; Smith-Sivertsenet al, 2009; Reddy et al 2004) in studies exploring impact of biomass use on lung functions. 
Factors Associated with Impaired Lung Function among Pregnant Women in Selected Rural and Urban Settings of the Copperbelt Province of Zambia

The current study findings showed that primigravida was more likely to have an impaired lung function compared to the multigravida. This observation is consistent with the study conducted elsewhere by Grindheim et al., 2012 in which spirometry was reported to be higher among the multigravida compared to the primigravida with results indicating that $\mathrm{FVC} \%$ are significantly higher in multigravida compared with primigravida women. The finding in our current study maybe due to the fact that primigravida women have less concern for factors that may affect them during pregnancy compared to the multigravida women. For instance, multigravida women might avoid emissions with exposures that might affect the unborn child therefore avoid activities such as cooking using biomass in less ventilated areas compared to multigravida women.

Despite other studies elsewhere (Gunnell, 2003; Lin et al, 2006; Baines et al, 2015) reporting the association of impaired lung function with factors such as blood pressure,smoking and body mass index, our current study did not find the association with any of them both in bivariate and multivariate analyses. However, a study by (Hole, 1996)in the Renfrew and Paisley survey was comparable to our findings in that it did not also find any relationship between impaired lung function and blood pressure. A number of other factors have been implicated for impaired lung function, however, our current study only found two factors as being independently associated with impaired lung function.

\section{ConCLUSION}

Preservation of lung health before and during pregnancy through targeting the modifiable risk factors identified in this study is a key research priority. Poor women living in developing countries using biomass for cooking and heating houses should form a priority group for targeted empowerment and information to opt for less polluting fuel types such as liquefied paraffin and electricity. The intervention in this regard is a significant public health practice as it will ensure good cardiovascular health in the mother and avoid related adverse pregnancy outcomes.

\section{Limitation}

Some women didn't satisfy the American Thoracic Society (ATS) standards for a good spirometry, however ATS guidelines allow for the use of data from unacceptable or nonreproducible maneuvers at the discretion of the interpreter. Since most of the failures were end-of-test related, the $\mathrm{FEV}_{1}$ levels are likely to be valid. Our results serve to emphasize the importance of effective training and quality assurance programs to the provision of successful spirometry in primary care practice.

\section{REFERENCE}

[1] Baines KJ, Backer V, Gibson PG, Powel H, Porsbjerg CM. Impaired lung function is associated with systemic inflammation and macrophage activation. European Respiratory Journal 2015 45: 557-559.

[2] Min KB, and Min JY, Reduced Lung Function, C-Reactive Protein, and Increased Risk of Cardiovascular Mortality.Circ J 2014; 78: 2309 2316

[3] Sabia S, Shipley M, Elbaz A, Marmot M, Kivimaki M, Kauffmann F, et al. Why does lung function predict mortality? Results from the Whitehall II Cohort Study. Am J Epidemiol 2010; 172: 1415 $-1423$.

[4] Gan WQ Man SF, Senthilselvan A, Sin DD. Association between chronic obstructive pulmonary disease and systemic inflammation: A systematic review and a meta-analysis. Thorax 2004; 59: $574-580$.

[5] Cox DR. Regression models and life tables.J R Stat Soc (B)1972;34:187220.

[6] Hole DJ, Watt GCM,Davey-Smith G, Hart CL, Gillis CR , Hawthorne VM Impaired lung function and mortality risk in men and women: findings from the Renfrew and Paisley prospective population study. BMJ 1996;313:711

[7] Lin WY, Yao CA, Wang HC, Huang KC, Impaired Lung Function Is Associated with Obesity and Metabolic Syndrome in Adults. Obesity 2006 Volume 14, Issue 9 Pages 1654-1661

[8] Martínez-García MA, Soler-Cataluña JJ, PerpiñáTordera M, Román-Sánchez P, Soriano J.Factors associated with lung function decline in adult patients with stable non-cystic fibrosis bronchiectasis. Chest. 2007 Nov;132(5):1565-72.

[9] Eaton T, Wtthy S, Garrett JE, Whitlock R. M.L., Rea HH, Mercer J, Spirometry in Primary Care Practice; The Importance of Quality Assurance 
Factors Associated with Impaired Lung Function among Pregnant Women in Selected Rural and Urban Settings of the Copperbelt Province of Zambia

and the Impact of Spirometry Workshops. Chest Journal1999Volume 116, Issue 2, Pages 416-423

[10] Ebi-Kryston K. Respiratory symptoms and pulmonary function as predictors of 10-year mortality from respiratorydisease,cardiovascular disease, and all causes in the Whitehall study. JClin Epidemiol1988;41:25160.

[11] CookDG, Shaper AG. Breathlessness, lung function and heart attack.Eur Heart J1988;9:121522.

[12] Kannell WB, Hubert H, Lew EA. Vital capacity as a predictor of cardiovascular disease: the Framingham study.Am Heart J1983;331:3158.

[13] Strachan DP. Ventilatory function as a predictor of fatal stroke.BMJ1991; 302:847.

[14] Tockman M, Comstock G. Respiratory risk factors and mortality: longitudinal studies in Washington county, Maryland.Am Rev Respir Dis1989;140:S56-63.

[15] Siziya S, associations of cement dust with occurrence of respiratory conditions and lung function, East African Journal of Public Health Volum 2 Number 1 April 2005

[16] Shonga T and Siziya S, Association between exposure to fuel and respiratory health among fuel attendants in Ndola, Zambia. Asian Pac. J. Health Sci., 2015; 2(4): 27-32

[17] Kurmi OP, Devereux GS, Smith WC, Semple S, Steiner MF, Simkhada P, et al. Reduced lung function due to biomass smoke exposure in young adults in rural Nepal. EurRespir J. 2013;41:25-30.

[18] da Silva LF, Saldiva SR, Saldiva PH, Dolhnikoff M. BandeiraCientíficaProject.Impairedlungfunction in individuals chronically exposed to biomass combustion. Environ Res. 2012;112:111-7.

[19] Sümer H, Turaçlar UT, Onarlioğlu T, Ozdemir L, Zwahlen M. The association of biomass fuel combustion on pulmonary function tests in the adult population of Mid-Anatolia. Soz Praventivmed. 2004;49:247-53.

[20] Rinne ST, Rodas EJ, Bender BS, Rinne ML, Simpson JM, Galer-Unti R, et al. Relationship of pulmonary function among women and children to indoor air pollution from biomass use in rural Ecuador. Respir Med. 2006;100:1208-15.

[21] Pope D, Diaz E, Smith-Sivertsen T, Lie RT, Bakke P, Balmes JR, Smith KR, and Bruce NG. Exposure to Household Air Pollution from Wood Combustion and Association with Respiratory Symptoms and Lung Function in Nonsmoking Women: Results from the RESPIRE Trial, Guatemala. Environ Health Perspect; 2015: vol. 123 DOI:10.1289/ ehp. 1408200

[22] Bruce N, Perez-Padilla R, Albalak R. Indoor air pollution in developing countries: A major environmental and public health challenge. Bull World Health Organ. 2000;78:1078-92.

[23] Smith-Sivertsen T, Díaz E, Pope D, Lie RT, Díaz A, McCracken J, et al. Effect of reducing indoor air pollution on women's respiratory symptoms and lung function: The RESPIRE randomized trial, Guatemala. Am J Epidemiol. 2009;170:211-20.

[24] Reddy TS, Guleria R, Sinha S, Sharma SK, Pande JN. Domestic cooking fuel and lung functions in healthy non-smoking women. Indian J Chest Dis Allied Sci. 2004;46:85-90.

[25] Grindheim G, Toska K, Estensen M, Rosseland L. Changes in pulmonary function during pregnancy: a longitudinal cohort study. BJOG 2012; 119:94-101.

[26] Gunnell D, Whitley E, Upton MN, McConnachie A, Smith D G, Watt GCM, Associations of height, leg length, and lung function with cardiovascular risk factors in the Midspan Family Study. J Epidemiol Community Health 2003;57:141-146

Citation: David Mulenga, MPH, Seter Siziya, PhD. Factors Associated with Impaired Lung Function among Pregnant Women in Selected Rural and Urban Settings of the Copperbelt Province of Zambia. Open Access Journal of Internal Medicine. 2018; 1(1): 32-40.

Copyright: (c) 2018 David Mulenga, MPH, Seter Siziya, PhD. This is an open access article distributed under the Creative Commons Attribution License, which permits unrestricted use, distribution, and reproduction in any medium, provided the original work is properly cited. 